\title{
Sedentary topography: the impact of the Christian Mission Society's 'civilising' agenda on the spatial structure of life in the Roper Region of northern Australia
}

\section{Angelique Edmonds}

Near the Hodgson River in Australia's Northern Territory stands a series of buildings, established initially during cattle station development and now constituting the Aboriginal settlement of Minyerri. In July 2003 the population had swollen considerably for a funeral ceremony. We waited by the women's camp a few kilometres from town, the crowds forgotten in the gravity of our anticipation. A breeze caught the edge of a hanging tarpaulin and the makeshift wall screening the women from view billowed momentarily, exposing their white faces and their application of more white body paint to cover themselves. They had been living under this makeshift shelter for some weeks now and would shortly participate in a ceremony that marked their return to town for the first time since the death of their kinsman.

Hours later, as the ceremony for their return began, the group of women emerged from beside a pink colourbond-clad house at the edge of the settlement. Their faces and bodies remained hidden from public view under an assortment of bed sheets. Other women acted as their guides leading them down the driveway, across a yard and through an opening in the wire fence marking the boundary of that block and the threshold to the more public 'street'. This was accompanied by the singing and clapsticks of men moving in a group just ahead of them. As they proceeded to a piece of ground marked by a group waiting for them, onlookers gathered in the front yards of neighbouring houses, resting against fences, sitting on or beside abandoned rusted out vehicles and crammed into any shade that was available.

I evoke this episode as a situated example of the continuing negotiation and inventive adaptation by groups of Aboriginal people living in remote settlements. In these places surrounded by vast expanses of country, the spatial structures imposed by the boundaries and thresholds of an essentially static built environment appear to be at odds with the versatility and adaptive mobility of traditional windbreaks and less permanent shelters readily adjusted to meet 
seasonal, familial and contextual changes. Yet, while the built environment appears static, mute and unresponsive to changes in context by comparison with mobile dwellings, in the greater temporal span that is drawn into focus by the death of a kinsman, the built environment begins to be revealed as a relatively transparent and temporary intervention upon an infinitely more enduring ground; that of the Land itself. As this paper will discuss, Land is the deepest temporal background for Aboriginal people in the Roper Region, determining institutions of behaviour and thus constituting the order of life. As this paper's example of ceremony surrounding the death of a kinsman will illustrate, maintaining the ontological primacy of the Land is imperative to the sustenance of life. ${ }^{1}$

The staging of a ceremony ensuring the safe re-entry into public life for the kin of a recently deceased member of the community is a phenomenon that goes to the heart of a community's beliefs regarding the structure of their orientation to the world and their collective response to dealing with the drama of human finitude. This ceremony, enacted as it was amongst the colourbond-clad houses, front yards, driveways, wire fences and abandoned vehicles of the settlement, in fact represents a moment within a deeper conflict confronting the heart of an Indigenous way of being and orientation to the world in contemporary Australia. It offers a moment of cross-cultural significance whereby an indigenous practice that concerns the preservation of the ontological primacy of Land (which continues to structure orientation to the world for many Alawa ${ }^{2}$ people in the region), occurs within the imposed colonial topographical order of sedentary life. The ceremonies enacted that day ensured the maintenance of order and balance and the enduring efficacy of the Land in continuing to sustain life. This is not understood as an abstract concept but in terms of the specific country of the deceased and the relational structure between his kin and their responsibilities to him and his country. Before exploring further the significance and practice of the ceremonies that day, it is necessary to discuss the context in which static, built living environments, that clearly advocate a bias in favour of sedentary life, were introduced to this region.

Colonial exploration in the Roper River region, where the Hodgson is located, began in 1841 and expanded considerably in 1870 with the establishment of the Overland Telegraph line. ${ }^{3}$ The Land on which Minyerri is situated was set aside as a cattle station in 1884 and named Hodgson Downs, an alternative name still used interchangeably for both the contemporary settlement and station. ${ }^{4}$ After a series of individuals' difficulties in establishing various pastoral enterprises in the region, a single company, the Eastern and African Cold Storage Company Ltd, acquired Hodgson Downs in 1903 along with all unleased and previously abandoned pastoral leases in the region. 'Having no intention of allowing Aboriginal resistance to prevent them from carving out their huge pastoral 
empire, the company determined to exterminate all Aboriginal people of the region'. ${ }^{5}$ Merlan writes that 'the Eastern and African' engaged in what was apparently the most systematic extermination of Aborigines ever carried out on the Roper. ${ }^{6}$ Quoting Bauer, she continues, 'this was probably one of the few authenticated instances in which Aborigines were systematically hunted. For a time, the company employed two gangs of 10 to 14 blacks headed by a white man or half caste to shoot the wild blacks on sight' ${ }^{7}$ For the Aboriginal people of the region, during this period the only way to escape death at the hands of hunting parties despatched by the primary pastoral company, was either to live under the patronage of station owners, or retreat into the safety of the rugged and impenetrable rocky hill country of southern Arnhem Land. Yet not every group had such choices; people along the valley of the Roper River in particular did not have the option of falling back to mountain strongholds. ${ }^{8}$

In 1908, the Church of England established the Roper River Mission through the administration of the Christian Mission Society. The 'Eastern and African' ceased operation in the same year and both events are remembered by Aboriginal people of the region as marking the beginning of peaceful relations. ${ }^{9}$ The charge (instructions) delivered to the missionaries in Melbourne in 1908 shortly before their departure, made it clear that the objectives of the mission were to be both spiritual and practical. The missionaries were bringing both 'Christianity and civilisation' ${ }^{10}$ Yet the mission was perceived by the local people as a sanctuary, within the protection of which they believed they were safe from European violence. By 1909, over 200 people had gathered at the mission, the remnants of the Mara, Wandarang, Alawa, Ngalakan and Ngandi tribes, as well as the southernmost members of Rembarrnga and Nunggubuyu tribes. ${ }^{11}$

The first missionaries at Roper led by Rev. Huthnance faced the same problem that missionaries all over Australia faced: how to maintain the mission program when the resident population varied in its make-up and fluctuated in numbers. Hunting and gathering people must hunt and gather to survive, and so the basic requirement to induce Aboriginal people to reside at their mission was food. While the longer-term strategy was to create a community self-sufficient in its own agriculture and livestock, in the shorter term, the mission could only retain people by providing food, thus the mission rapidly followed missions all over Australia in providing food for school children to keep them in school. ${ }^{12}$ The mission very rapidly became an organized institution in which a daily routine including a daily service was strictly regimented. ${ }^{13}$ The emphasis on the discipline of the daily service was not a universal mission strategy even within CMS worldwide. It was a feature of 'industrial missions', the name given to the work-oriented missions to supposedly 'primitive' or 'uncivilised' people, particularly nomadic, tribal people. It was presumed that such people had to be civilized, so missions tended to emphasise the training of people to adopt a settled 
agricultural lifestyle. ${ }^{14}$ By the end of 1908, three substantial buildings had been erected for the staff, stores and school. ${ }^{15}$ The physical facilities were little more than basic shelters for the first 40 years of CMS missions, since construction was with local materials and at first only a few buildings had corrugated iron or a floor. ${ }^{16}$ Earthen floors created through a technique using rammed ant bed were common. Despite the simple structures, the spatial demarcation employed was an element of great significance in the conversion project. As the Mission station developed, the mission area was distinguished by a boundary fence surrounding about seven buildings that accommodated the missionaries, the school, church, workshop, ablutions blocks, a boy's dormitory and a girl's dormitory. ${ }^{17}$ In the early years of the Mission, parents were not permitted to stay inside the mission boundary. ${ }^{18}$ Such practices were common in many Aboriginal missions throughout Australia where missionaries anticipated greater success at conversion by segregating families and concentrating (initially at least) on conversion of the children to Christianity. ${ }^{19}$

Outside the Roper River mission were the huts of the Aboriginal people who worked on the mission, and beyond those, on the banks of the river, was the 'camp' where the visiting 'bush' Aboriginal people stayed. ${ }^{20}$ In most missions there was an agreed boundary of some kind, distinguishing the 'camp people' or the 'bush blacks', sometimes referred to simply as 'myalls', as distinct from 'mission people'. The 'camp people' were treated quite differently from the 'mission people', undoubtedly as part of the 'civilising' goal. As one of the Roper missionaries recalled, one of the more severe punishments for girls in the Roper dormitory was to be treated like a 'camp person' ${ }^{21}$ Thus, the conversion project employed, promoted and cultivated values that favoured specific dwelling styles rather than others. It structured Aboriginal people's living environment by overlaying the Land with boundaries distinguishing areas marked by differences in expected conduct and use: a new spatial ordering for the Land. This concurs with Trigger's descriptions of the influence of Christianity in Domadgee, where he states 'people understood the spatial order of the mission in terms of places where thought and behaviour were either expressed or sheltered, from non-indigenous scrutiny and correction' ${ }^{22}$ 


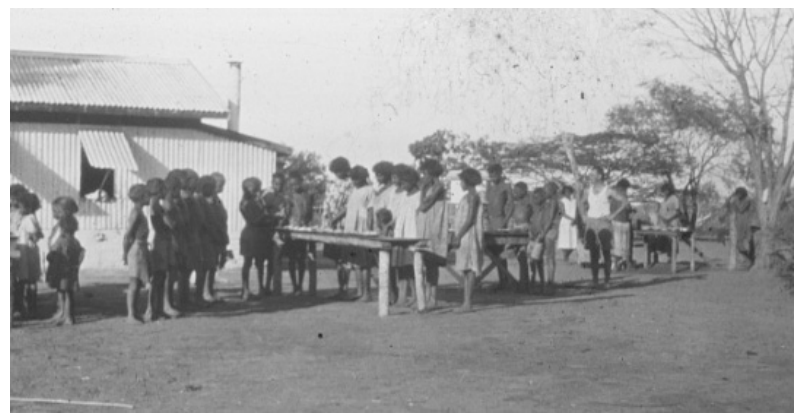

Figure 9.1: Children lined up for breakfast at Roper River Mission, no date. Courtesy of the CMS Hart collection, Darwin.

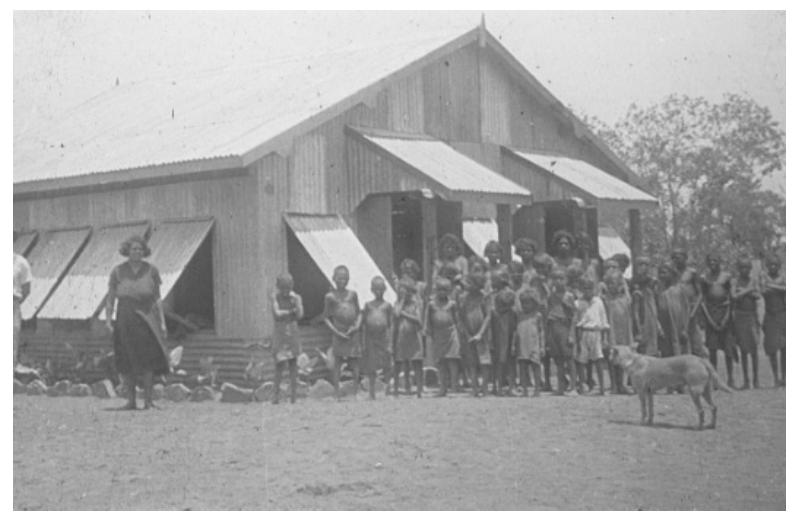

Figure 9.2: The new School at Roper Mission 1937.

Courtesy of the CMS Hart collection, Darwin.

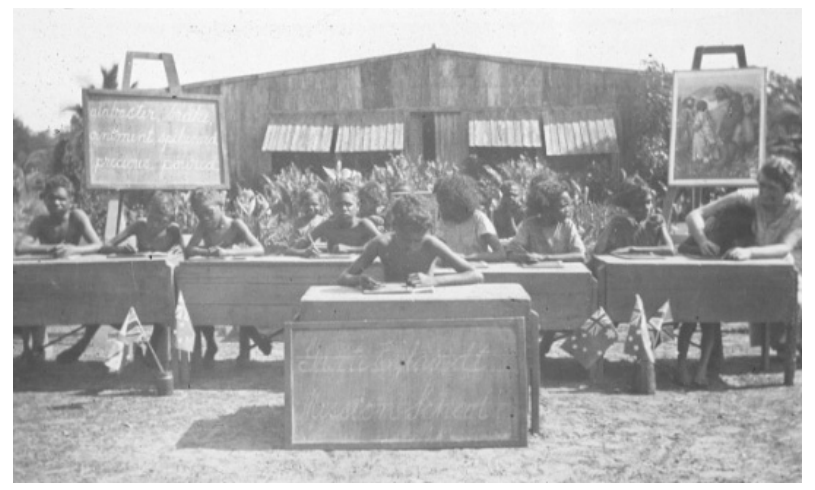

Figure 9.3: School children with work outside the school, no date.

Courtesy of the CMS Hart collection, Darwin. 
The deceased man at the focus of the funeral ceremony described at the start of this paper grew up at Roper Mission, as did many of his contemporaries and their families. Many of those in attendance at the funeral also either grew up, or are descended from relatives who grew up at the Roper Mission. There are three reasons why this is important in the context of this paper.

Firstly it is important as the context for understanding the continuing influence that mission life has had on structuring the lives of those at Minyerri. It is only recently that many Alawa people returned from the settlement of Ngukurr, the contemporary settlement at the site of the former Roper mission, to live on their country, so the Mission influence remains a significant element in the structure of their lives. It was not until 1990, when (the former) Aboriginal Torres Strait Islander Commision (ATSIC) purchased Hodgson Downs station (where the settlement of Minyerri lies) for the Hodgson Downs Community Incorporated, made up of the traditional owners, the Alawa people, that the majority of current residents returned to Minyerri. At the time the sale was negotiated there were 170 people in residence. The previous owners of the station had a white manager in residence who padlocked all the access gates on the property to limit the movements of the Aboriginal people and to keep them under control. When the sale was being negotiated, the people were insistent that they never again wanted to be subjected to white management. ${ }^{23}$ In 1992 there were 210 people living at Hodgson Downs, with numbers increasing as people returned from Ngukurr and other nearby settlements. By November 2003, a few months after the ceremony described in the opening of this paper, Minyerri's population was recorded as 450 .

The second reason the Roper mission's influence is important in the funeral ceremony at Minyerri, lies in the evident commitment by people in the region to the maintenance of highly mobile lifestyles, linking kin between Minyerri and Ngukurr. More than 100 people were in attendance at the funeral business at Minyerri that day. Many of them had travelled from Ngukurr and other surrounding settlements specifically to be present for the funeral and associated business, affirming the vast webs of kin relatedness and individual roles and responsibilities within that web. Inter-community mobility in the Roper River region is frequent and important. Movement related to funeral business (often several weeks in duration) is but one of many reasons for this mobility. This has been maintained despite the efforts of the missionaries to impose an exclusively sedentary life and affirms the people's desire to retain autonomy over the order of their lives; a part of a demonstrable resilience and endurance of specific cultural practices. 
This is further emphasised when it is remembered that the performance of traditional funeral ceremony business was forbidden at the Roper Mission. ${ }^{24}$ Thus, thirdly, the maintenance and endurance of the knowledge of funeral ceremony business through the generations despite nearly 60 years of missionary prohibition is further evidence of extraordinary tenacity and commitment to the maintenance of culture. The decision by the deceased's family and contemporaries, to mark his death in both the traditional way and the Christian way is an honour indicative of his capacity to operate in both spheres and to be acknowledged and respected in the appropriate ceremony for each way.

While there is no doubt that the mission's establishment was motivated by a compassion for the Aboriginal people of the region, without which they may not have survived, the impact of the 'civilising' agenda has left a lasting legacy. The CMS and the majority of its missionaries in Australia were accustomed to believing that there was something particularly Christian about changing people's lifestyle from being nomadic hunters and gatherers to being settled farmers. An article in The Open Door, the CMS journal, in 1941 suggested that this was a kind of spiritual healing. 'The healing of the body gives a great opportunity for the healing of the soul. If the Aborigines are to be prepared to take their place in our civilization, they must be brought from a nomadic food-gathering existence to a food-producing village life. ${ }^{25}$ Hunting, fishing and digging yams were not work. Furthermore, building and farming were considered somehow more Christian, whereas hunting and fishing were less Christian. An attitude prevailed where work and the Gospel were intertwined and even indistinguishable. The 'gospel of work' was the attitude and understanding imparted to Aboriginal people when missionaries engaged in training them in the various labouring tasks necessary to create a self supporting, European style community. ${ }^{26}$

One incident reported in a CMS annual illustrates this further:

One boy requested permission to marry one of the girls, and had now started to build his own house and prepare his garden, with a view to being able to keep himself and family - with the mission behind him to give a hand if he stumbles. We are hoping this couple will be the beginning of our long planned for village settlement, and that others will soon follow in their steps. ${ }^{27}$ 


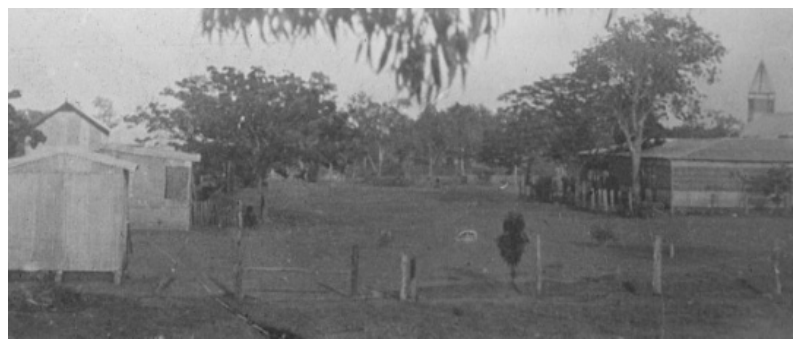

Figure 9.4: Mission station at Roper River, no date.

Courtesy of the CMS Hart collection, Darwin.

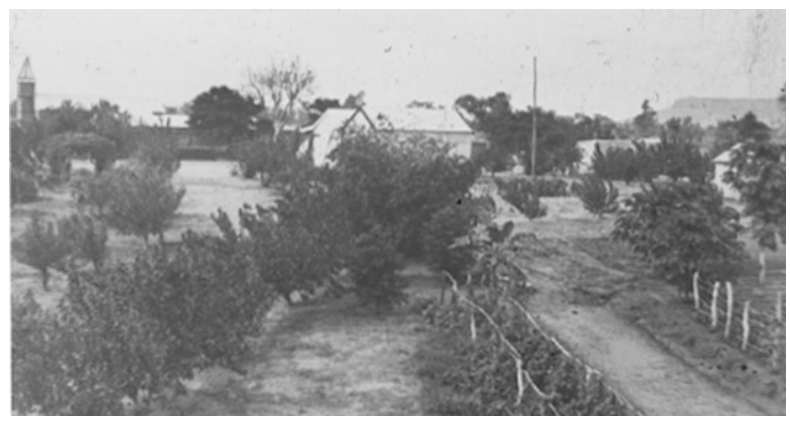

Figure 9.5: Roper River mission showing gardens, no date.

Courtesy of the CMS Hart collection, Darwin.

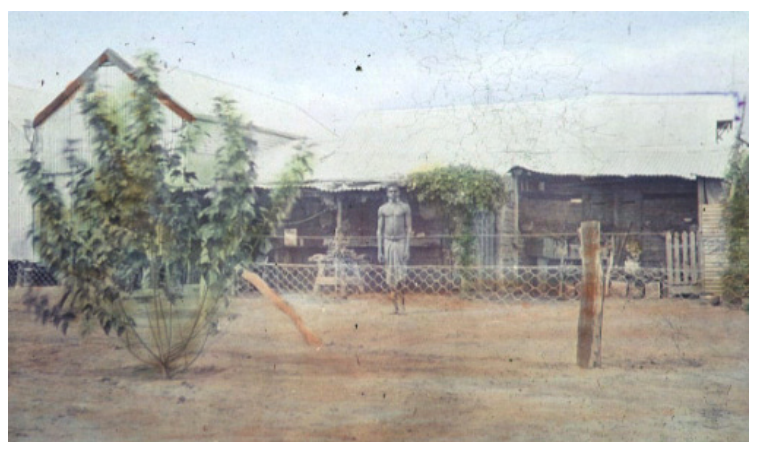

Figure 9.6: Mission quarters at Roper River, no date.

(Handcoloured glass slide image, courtesy of the CMS Hart collection, Darwin)

These images are reproduced courtesy of Keith Hart from glass plate positives. Their quality is a result of this source. 
As Harris discusses in his history of the CMS presence in the Roper Region, this vision died hard and as recently as the 1960s there were still a few missionaries who dreamed of the self-supporting family unit and spoke of it in sometimes paternalistic terms. ${ }^{28}$ For Aboriginal kin groups made up of family extended across generations with extensive group responsibilities and obligations, the Christian order which revised the family dwelling unit to parents and children, required a radical reorientation, with significant consequences for the passing of culture and knowledge between extended kin. Harris concedes that it became evident 'the idealized Christian Aboriginal village, with happy, stable Aboriginal families living in their modest homes and working their little agricultural plots, was never going to happen. CMS was reluctant to let go of the notion of the self-sufficient village altogether. In the $1950 \mathrm{~s}$ and 1960s the idea of a self-sufficient family gave way to a self-sufficient community' ${ }^{29}$

During the years when CMS missionaries either believed they were protecting a dying race, or later, when they believed they were preparing Aboriginal people for an English speaking future, they regarded Aboriginal culture as fairly irrelevant. It was only when CMS started appointing linguists that missionaries began to have the opportunity to understand the local culture and society. ${ }^{30}$ Since the way in which leadership is exercised in Aboriginal society differs markedly from the way it is exercised in western democratic society, Harris ${ }^{31}$ suggests that with the exception of his father, Len Harris, very few, if any, missionaries really knew who the significant people were in community decision-making. Earl Hughes, a reverend appointed to Numbulwar, another CMS mission north of the Roper wrote to Harris about the way in which autocratic white mission superintendents ignored tribal leadership, thus contributing hugely to breakdown in community order and discipline' ${ }^{32}$ The ways in which such authority continued to be expressed, despite the ignorance of the missionaries, draws attention to the existence of a concurrent expression of community behaviour, escaping the attention of the missionaries, doubtless continuing to assert its own order over the lives of the residents of the mission settlement. Despite the apparent complicity of the mission population in adopting the missionaries' imposition of structure and order, a traditional cultural order was maintained and the deceased man at the focus of the funeral ceremony described above is one such example of this. He was a 'big boss' for culture. The traditional cultural order with respect to country and ceremony continues still, and is present and publicly expressed in moments such as the negotiation and enactment of a funeral ceremony.

In Minyerri and Ngukurr both Christian orientations to the world and traditional kin-based Aboriginal orientations of relatedness continue to exist concurrently. The contemporary ceremonies enacted to mark the passing of human life have come to embody a significance in which an intersection of orientations to the 
world and belief structures is continually expressed, negotiated and redefined. Each of these negotiations occurs relative to the deceased individual and the web of relatedness their death draws, particularly from the three contemporary trajectories of authority; Church, State, and Culture. The latter of these three was once the only basis for the allocation of authority and responsibility. While it may be imagined that as a system of authority it was doubtless not innocent of political manoeuvring itself, the contemporary concurrent negotiation of the politics of all three systems of authority reveals an intensely complex and potentially volatile phenomena in marking the death of a kinsmen, as those related to an individual in any of these three spheres may seek to have their relationship to the deceased acknowledged publicly.

For this reason, contemporary funeral ceremonies and the effort that accompanies their negotiation and enactment involve a myriad of political negotiations. My current focus is the manner in which the spatial arrangement of such procedures is taken up in expressing relationships between those still living, the expressions of authority they seek to make public through the enactment of the funeral ceremony, and how these negotiations between the living invoke aspects of interpreted significance in their relationship to the deceased in order to re-situate themselves politically. Since communities of Aboriginal people have been living in built environments such as Minyerri and Ngukurr for just less than a century, the ways in which those built environments are taken up by residents in expression of social relationships, casts light upon understanding the impact that settlement life continues to have upon those who live there, how those environments develop through metamorphosing usages, and the impact their usage has on the expression of relatedness between kin and country.

Both historically and in contemporary Minyerri and Ngukurr, particular dwellings or landmarks often stand as a significant marker of country or kin affiliation. In mission times in Ngukurr, the residential camps were spatially separated according to people's affiliation with country, which naturally were also linguistically differentiated. A distinction prevailed in the minds of residents between the 'top camp', 'middle camp' and 'bottom camp'. 33 Each camp embodied its own distinct identity linguistically and socially in relation to the residents it housed and the country from which they originated. Accordingly top camp was Rittharngu camp, middle camp was Nunngubuyu and bottom camp was Ngandi, Wandarang with Mara and Alawa people living nearest the River. ${ }^{34}$ This distribution is indicative of these groups' orientation to country; since top camp is the most northern location, where the most northern oriented group, the Rittharngu were camped, and the Nunngubuyu, just south east of them in country, camped south-east of them in the settlement. Ngandi country is in the middle of all these groups, thus they were in middle camp in the settlement. Wandarang are coastal people and their affiliations with Mara and Alawa people, both of whose country lay south of the Roper meant they camped 
together, and usually Mara and Alawa people were the most southern in the camp, closest to the river and their country on the other side of the river. ${ }^{35}$

While top, middle and bottom camp remain spatially distinct in Ngukurr in contemporary times, generations of intermarriage between the language groups have intensified the associations that any single household may have to several tracts of country, relative to the affiliations of kin who live there. In other Arnhem Land communities, houses have been named after specific country and accordingly will house those with an interest or affiliation with that country. ${ }^{36}$ A yard area and communal street area adjacent to a series of houses may have a significance affiliated with certain clans or their country and affiliations. This can occur in an enduring or ongoing sense and/or for a specific temporal period such as during a ceremony. Thus despite the imposition of a grid structure of streets delineating suburban spatial dwelling practices and boundaries, for residents, the spatial order and significance of places within the settlement continues to be structured by residents' relationships to country, kin and thus each other. The structure of living for residents could not be contained by the boundedness of the housing grid. Households are characterised by a constant fluid and evolving process of metamorphosis, in which relationships between individuals and affiliations with webs of kin are constantly negotiated and redefined in relation to disputes, conflict, changes in affiliation and context. Relocations between households are common and a necessary feature in the avoidance of conflict, or temporary resolution of disputes, or claims of sorcery or transgression.

The imposed settlement structure has radically altered the settings for opportunities in which political, ceremonial and cultural negotiation and expression occur and as a result residents constantly renegotiate and redefine the expression of authority on their own terms and thus in their own ways. In the contemporary situation of three systems of authority - Church, State and Culture - the stakes involved in funeral ceremony displays of authority are even more complex. The ways in which the settlement's built environment is adapted to this end, show an acute understanding of the importance of spatial relationships and contexts in situating phenomena. For example, the pink colourbond-clad house from beside which the women emerged, was chosen as an appropriate threshold from which they could embark on their re-entry into public life. The reasons for choosing that house over others was significant, and not an arbitrary choice, but rather one which expressed important aspects of authority, obligation and responsibility between kin and this is expressed in relation to the spatial planning and houses belonging to other kin. Before exploring this in greater depth, it is helpful to contextualise the cultural significance of the events themselves. 
Upon the death of a member of the community, the place where they slept is cleared and all their possessions destroyed or removed. This often means that whole families will move house. The house where the deceased person was residing may remain empty for some time until an appropriate cleansing ceremony marks it as able to be inhabited again. It is understood that when an individual is born their spirit has come from a particular place within the earth's features and in order to maintain the enduring life source of that place and keep that country safe, upon an individual's death their spirit must return to it's place of origin. The name of the deceased is not spoken but is replaced by a speech restriction term, lest the speaking of his name should cause his spirit to linger. The immediate relatives of the deceased must move away from their usual living place and conceal themselves, so that if his spirit came looking for them, they would not be recognized. Seeking this concealment, as described at the beginning of this paper, in the women's camp located outside town, they were covering their skin in white body paint to aid in the safe return passage for the spirit of the deceased to his country. In the case of the death at Minyerri, the dwelling of the man was evacuated to ensure that his spirit returned to his country and his relatives hid to ensure that his spirit did not attempt to find them and stay attached to the affiliations of his life. Once the body of the deceased has been buried, his relatives may return to the settlement in a ceremony that marks their absolution from the period requiring concealment. This is followed by a ceremony for the house of the deceased that 'cleanses' it or marks it as safe to inhabit again. $^{37}$

The pink colourbond-clad house from beside which the women at Minyerri emerged during ceremony was chosen because it was located at a sufficient distance; one of the farthest away from the house of the deceased, and also on the perimeter edge of the settlement. Thus it was marked as a threshold of entry back into public settlement life and simultaneously located as far as possible from the deceased's house, which was yet to be 'cleansed'. The relationship between the occupants of that house and the deceased are also of significance. Reciprocal roles of responsibility for country and ceremony are inherited from one's parents (and grandparents) and the significance of these roles depends on the context. In the Roper region the roles carry the names Minggirringi, Junggayi and Darlnyin and each confers different responsibilities in relation to specific sites, land and (by inference) individuals. The terms are sometimes translated into English as 'owner', 'manager' and 'ranger' respectively. An individual is Minggirringi for the sites, ceremonies, ancestral beings and country associated with his or her father and father's father. An individual is Junggayi for sites, ceremonies and historic ancestors associated with his mother's and mother's father's country and father's mother's (brother's) country. Darlnyin are sometimes described as 'half' Minggirringi, 'half' Junggayi, and will be Darlnyin for sites, ceremonies and ancestral beings in his mother's mother's (brother's) country. ${ }^{38}$ 
The reciprocal relationships, responsibilities and obligations conferred by these roles in relation to country and kin are called forth in different ways relative to context. In the context of the death of a kinsman, the spirit of the deceased must be returned to the country for which he is Minggirringi and the Junggayi of the deceased have an obligation to organise the ceremonies associated with his/her death, since it is their role to ensure that the originating country of the deceased is properly managed, and ensuring the safe return of his spirit to that country is an important part of that management obligation.

The most senior occupant of the pink colourbond-clad house was the most senior Junggayi for the deceased and his country, and thus this Junggayi's house by extension, became the appropriate place, symbolically from which this specific set of ceremonies could be conducted due to the occupant's close reciprocal kin affiliation and responsibility. Thus although this particular country where Minyerri stands has been overlaid with a (rough) grid structure of streets, determined by the imperative of the settlement's 'delivery of services' to individual houses which delineate numerous zones of privacy scaled from the innermost private dwelling practices of 'nuclear' families through to the public life of the street, the residents of Minyerri attribute and distinguish the significance of different places within the settlement using a different structure of order, in fact an order inherent in the Land that existed before the built environment was manifest.

Earlier in the day, I had witnessed the Anglican funeral service (for the same individual) and was struck by the apparent incongruity between the mobile belief structure, that appears to be applicable anywhere, of the Christian doctrines that had found their way to this region, and the particularity of location to which Aboriginal beliefs are anchored. The particularity of location of Aboriginal beliefs in the Roper Region means that the significances of particular places are unique and are unable to be overlaid, imposed upon or transported to other Land (as opposed to the possibility of this in Christian belief structures). The continuation of life requires the nurturance of specific places as the source of life, as the place from whence spirit emerges to give life to human form. Thus it is the particularity of embodiment and a resistance to the mobility offered by the conceptual which allows that continuity and the ontological primacy of Land to be maintained. Unlike the Christian doctrines, applicable in any location just like the conceptually derived Cartesian 'grid' of structures in a settlement, the significance of 'place' for Aboriginal people in the Roper region, as for Aboriginal people in many other areas in Australia, is particular to specific locations and always relationally anchored to webs of other specific places. ${ }^{39}$

So as we witnessed the lowering of the casket and listened to the Aboriginal Anglican minister's sermon promising eternal life in a heavenly city, I wondered, looking at the buildings surrounding us, what exultation these people were 
supposed to feel might lie in the promise of an afterlife in the 'ethereal' city of heavenly Jerusalem, when their ontological continuum is understood as so connected to the Land, the ground and the particularity of place. Since many people in the region identify as Christian, their capacity to incorporate aspects of the Christian doctrines, while maintaining their adherence to the enduring order of the Land demonstrates their adaptive capacity. The way in which the funeral ceremony was conducted according to customs drawn from both belief structures is indicative of this.

In the Minyerri ceremony the women were led away from the pink colour-bond clad house to an area of ground marked by a group evidently waiting for them. The cleansing procedure continued and the women were absolved from the period requiring concealment; the white paint was washed from their bodies, then each individual was 'smoked', and others of the community, children included, were summonsed to participate in this part of the ceremony if they wished. Branches of leaves were lit, and their burning swiftly smothered, producing smoke that continued for some time. The smoking branches were then waved about the body ensuring the cleansing from the presence of any unwanted spirits. Earth from the ground on which they stood was then placed firmly in the hand of the individuals concerned, and this marked the closure of this part if the ceremony.

It appeared that this last action consolidated their presence and grounded the women in their current location, both temporally and spatially. At that moment it seemed clear that the layout of the surrounding buildings appeared only to represent an order of relatedness that would always be secondary despite colonial attempts continued in contemporary times in structuring Aboriginal lives according to the institutions of behaviour attendant upon settlement life. The order of relatedness for the Aboriginal residents in Minyerri and neighbouring Ngukurr relies primarily on being grounded first and foremost by the Land. While the imposition of built environments in this region remain as structures seeking to re-order the lives of their inhabitants, residents appear to take them up in ways that maintain an adherence to the order of the Land which precedes the built environment. The fixtures of the built environment continue to be taken up with inventive response by residents of the settlement in different contexts with differing political import and are appropriated in the expression and articulation of an order of relatedness between kin and country that has existed and continues to exist beyond the weathering of the corrugated iron cladding. 


\section{References}

Attwood, Bain 2000, 'Space and time at Ramahyuck, Victoria 1863-85', in Peter Read (ed.), Settlement: a history of Australian Indigenous housing, Aboriginal Studies Press, Canberra.

1989, The making of the Aborigines, Allen \& Unwin, Sydney.

Baker, Brett 2002, "I'm going to where-is-your-brisket": placenames in the Roper', in Luise Hercus, Flavia Hodges and Jane Simpson, (eds), The land is a map; Placenames of Indigenous origin in Australia, Pandanus Books, Canberra: 103-130.

Bauer FH 1964, Historical geography of white settlement in part of the northern territory, Part 2: The Katherine-Darwin region, CSIRO Report 64(1), Canberra.

Bern, John 1979, 'Politics in the conduct of a secret male ceremony', Journal of Anthropological Research 35(1): 47-60.

Dillon, Jane and Mark Savage 2003, 'House design in Alice Springs town camps', in Paul Memmott (ed.), TAKE 2 Housing Design in Indigenous Australia, Royal Australian Institute of Architects.

Edmonds, Angelique 2002, 'Approaching an understanding of the Yuendumu doors', M.Phil thesis, Architecture Department, Cambridge University, U.K.

Edmunds, Angelique 2007, 'Metamorphosis of Relatedness: the Place of Aboriginal Agency, Autonomy and Authority in the Roper River Region of Northern Australia', PhD thesis, The Australian National University.

Elkin, AP 1972, Two rituals in south and central Arnhem Land, Oceania Monograph 19, Sydney.

Harris, John 1998, We wish we'd done more: ninety years of CMS and Aboriginal issues in north Australia, Open Book Publishers, Adelaide.

1990, One blood: 200 years of Aboriginal encounter with Christianity - a story of hope, Albatross, Sydney.

Martin, David 1993, 'Autonomy and relatedness: an ethnography of Wik People of Aurukun, Western Cape York Peninsula', PhD thesis, ANU.

Merlan, Francesca 1978, "“Making people quiet" in the pastoral north: reminiscences of Elsey station', Aboriginal History 2(1): 70-106.

Morphy, Howard 1995, 'Landscape and the reproduction of the ancestral past', in E Hirsch and $\mathrm{M} \mathrm{O}^{\prime}$ Hanlon (eds), The anthropology of landscape: perspectives on place and space, Clarendon Press. 
Morphy, Howard and Frances Morphy 1981, 'Yutpundji-Djindiwirritj Land Claim', Northern Land Council.

Myers, Fred 1986, Pintupi country, Pintupi self: sentiment, place and politics amongst Western Desert Aborigines, Smithsonian Institute Press, Washington, D.C.

Ogden, Pearl 1992, From humpy to homestead, the biography of Sabu, narrated by Peter David Sing, compiled by Pearl Ogden, AIATSIS, Darwin.

Rose, Deborah Bird 1986, Nourishing terrains, Australian Aboriginal views of landscape and wilderness, Australian Heritage Commission, Canberra.

Rowse, Tim 1992, Remote possibilities: the Aboriginal domain and the administrative imagination, NARU, ANU, Darwin.

Trigger, David 1992, 'Whitefella comin'; Aboriginal responses to colonialism in northern Australia, Cambridge University Press, Cambridge.

1996, 'Blackfellas and whitefellas: the concepts of domain and social closure in the analysis of race relations', Mankind 16(2): 99-117.

\section{ENDNOTES}

${ }^{1}$ I attended the ceremony described at the request of adopted family, since I was working with people in the region at the time on a doctoral research project aimed at understanding the impact of sedentary life upon people's relationship to country and their capacity for agency in determining the order of their lives. Although this ceremony occurred early in my stay in the region, my understanding of events from that day grew in retrospect as my experiences as a permanent resident in the region afforded further understanding of the intricacies of the networks of relatedness of kin and country. For further discussion on the importance of Land, see Morphy 1995; Myers 1986; Rose 1996.

2 Alawa is the predominant language spoken by the residents of Minyerri.

3 Morphy and Morphy 1981: 4-5.

4 NTRS and NT Land Title records.

5 Harris 1990: 696

6 Merlan 1978: 87.

7 Bauer 1964: 157 as cited by Merlan 1978.

8 Harris 1990: 696-98.

9 Morphy and Morphy1981: 15.

10 CMA Instructions from Committee, delivered on Friday July 10th 1908, to Rev. J.F.G. Huthnance, Leader of the party, Mr R. D. Joynt, Mr Charles Sharp CMSF (as cited in Harris 1998: 9).

11 Harris 1936a: 236 as cited in Harris 1998: 11. John Harris, the author of these texts, was the son of Len and Margery Harris, CMS missionaries who worked in northern Australia. Their relations, Dick and Nell Harris were also contemporary CMS missionaries in the north of Australia. After John Harris' completion of the book One Blood in 1990, CMS approached Harris to write We Wish We'd Done More since he had significant knowledge and experience of the CMS's presence in the north of Australia and the structure and aims of the Mission stations.

12 Harris 1998: 326.

13 Harris 1998: 23.

14 Harris 1998: 27.

15 Annual Report of CMA of Victoria 1908: 9 CMSFA (as cited in Harris 1998: 23).

16 Harris 1998: 330.

17 Personal communication Gertie Huddlestons, Ngukurr, October 2004. 
18 Gertie Huddleston, 22 October 2004, interview at Old Mission.

19 See generally Trigger 1992; Martin 1993; Attwood 1989: 1-31, further verified in relation to Roper Mission in interview on 22 October 2004 with Gertie Huddleston, who was born at the old mission in the late 1920s.

20 Harris 1998: 141.

21 Mary Crome's diary as cited in Harris 1998: 24.

22 Trigger 1996: 114-5.

23 Ogden 1992: 122.

24 Interview in Ngukurr with Rev. Michael Gumbuli, Helen Rogers, Maureen Thompson, Betty Roberts and Roslyn Munur, 27 October 2004.

25 The Open Door 1941: 11, quoting a National Missionary Council leaflet, cited in Harris 1998: 205.

26 Harris 1998: 206.

27 The Church Missionary Gleaner, 1 Aug 1926: 20, cited in Harris 1998: 210-211.

28 Harris 1998: 211.

29 Harris 1998: 212.

30 Harris 1998: 156.

31 Harris 1998: 156.

32 Harris 1998: 156.

33 Personal conversations with Ngukurr residents in 2004 including David Daniels, Alan Joshua, John Joshua, Margaret George, Cherry Daniels, Betty Roberts, Freda Roberts, Gertie Huddleston.

34 Personal conversations with Ngukurr residents in 2004.

35 Northern Territory Archives Service, Christian Mission Society 873/P1 Box 1, 2 undated maps, read together with Traditional Language Regions map in Baker 2002.

36 Personal communication Peter Toner, ANU, 11 September 2003.

37 This was explained to me by my adopted family at the time of the ceremony and in discussion over the following 18 months as I sought to clarify my understanding of the way in which the structures of the built environment had been taken up and incorporated into existing practices ensuring the maintenance of the ontological primacy of the Land.

38 See Bern 1979; Elkin 1972; Morphy and Morphy 1981.

39 This understanding was gained through numerous discussions the author has had with Walpiri, Wandarang, Mara, Nunggubuyu, Ritharrngu and Alawa people in the Northern Territory and through sources consulted in the process of my $\mathrm{PhD}$ research. For discussion of these issues at greater length see Edmonds 2002 and 2007. 